\title{
Phytoremediation Mechanism of Sediment Contaminated with Pentachlorophenol by Aquatic Macrophytes
}

\author{
Liangyuan Zhao ${ }^{1, a}$, Weihua Zhao ${ }^{1 b}$, Weijie Guo ${ }^{1 c}$, Huan li ${ }^{1 d}$, Meng Long ${ }^{1 e}$ \\ ${ }^{1}$ Basin Water Environmental Research Department, Yangtze River Scientific Research Institute, \\ Wuhan 430010, China \\ azhaoliangyuannew@163.com, bzwh820305zwh@163.com, cguoweijie1986@163.com, \\ d270965844@qq.com,e415377031@qq.com
}

\begin{abstract}
Keywords: pentachlorophenol, phytoremediation, sediment, mechansim.
Abstract. In the present research, phytoremediation mechanism of sediment contaminated with pentachlorophenol (PCP) was investigated. Seven species of common aquatic macrophytes were used for remediating PCP contaminated sediment and those plants could significantly accelerate the degradation of PCP in sediments. Among all, Canna indica L. attained 98\% of PCP removal, and can be used as efficient alternative plant for remediation. Accumulation of PCP in plant biomass of canna indica L. only made a small contribution to the total removal of PCP. Through the analysis of PCP removal pathways, microbial degradation promoted by aquatic macrophyte was the main mechanism involved in the PCP contaminated sediment phytoremediation.
\end{abstract}

\section{Introduction}

Pentachlorophenol (PCP) has been widely used for killing snails, the only intermediate host of schistosome in water environment where schistosomiasis is epidemic in recent decades in china[1-2]. However, wide use of PCP on large areas has caused excessive PCP contamination in the sediment of water environment. PCP is a kind of persistent organic pollutants(POPs) and excessive levels of PCP will cause potential threat to the aquatic ecosystem and people's health[3-4]. Thus, control and removal is necessary to reduce the risk sediment contamination[5].

The emerging technology of phytoremediation, which has broadly applied prospects, is a promising remediation method for PCP treatment thanks to its ecological and economic sustainability[5-6]. In the present research, Seven species of common aquatic macrophytes were selected to screening efficient plants for phytoremediation of PCP contaminated sediment, and furthur research was conducted to investigate the mechanism involved in the phytoremediation by aquatic macrophyte with the best removal effect of PCP. The research results are believed to promote the development of ecological remediation of PCP contaminated environment in the polluted areas.

\section{Materials and Methods}

Materials. PCP $\left(\mathrm{C}_{6} \mathrm{Cl}_{5} \mathrm{OH}\right)$ used in the experiment was of $98 \%$ chemical purity $(\mathrm{AR})$ and standard solution of PCP was of HPLC grade. Samples of sediments without detectable PCP were collected from the $0-20 \mathrm{~cm}$ surface sediments at a local lake in Wuhan, Hubei province, China. And the basic physical and chemical properties of sediments were: $\mathrm{pH}, 7.86$; total nitrogen, $0.41 \mathrm{mg} / \mathrm{g}$; total phosphorus, $0.13 \mathrm{mg} / \mathrm{g}$; organic matter,3.38\%. Seven species of aquatic macrophytes, including Canna indica L., Acorus calamus L., Alisma plantago-aquatica L., Polygonum hydropiper L., Thalia dealbata Fraser, Iris tectorum Maxim., Cyperus alternifolius L., used in the experiment were collected from Wuhan xiushui ecological engineering co., LTD in Wuhan, Hubei province, China.

Phytoremediation Treatments Setup. For the experiment, preparation of PCP contaminated was followed as the previous research[5].10 $\mathrm{kg}$ of PCP contaminated dry sediments $(2 \mathrm{mg} / \mathrm{kg} \mathrm{dw})$ were loosely packed into planting pots $(0.3 \mathrm{~m} \times 0.4 \mathrm{~m} \times 0.3 \mathrm{~m})$. 6-10 individuals of seven species of macrophytes wih initial plant height of about $15 \mathrm{~cm}$ were transplanted to experiment pots at initial stage with the aim of obtaining an approximately equivalent amount of plant biomass per pot. Tap water was then added and kept at $4 \mathrm{~cm}$ above the sediments surface. The experiment ran for 120 days. 
Four treatments were established:(1)Sediment control(Sediments with PCP of $2 \mathrm{mg} / \mathrm{kg}$ without planting aquatic macrophytes). (2)Treatment group(Sediments with PCP at $2 \mathrm{mg} / \mathrm{kg}$ and planting aquatic macrophytes). (3)Microbe-inhibited sediment control(Sediments with PCP at $2 \mathrm{mg} / \mathrm{kg}$ with addition of $0.1 \% \mathrm{NaN}_{3}$ to inhibit the microbial activity). (4)Shading group(unplanted sediment with $\mathrm{PCP}$ at $2 \mathrm{mg} / \mathrm{kg}$ covered with aluminum foil to deprive of sunlight).Three replicate pots of each treatment were established.

\section{Chemical Analysis.}

PCP Extraction and Cleanup.Three replicate dried sediment samples of $5 \mathrm{~g}(\mathrm{dw})$ each were extracted with $30 \mathrm{~mL}$ of methanol for $30 \mathrm{~min}$ by ultrasonic extraction. This extraction was performed triple. The combined $90 \mathrm{~mL}$ of extract was deeply filtrated by glass microfiber Filters (GF/C, whatman) and then concentrated to about $3 \mathrm{~mL}$ by rotary evaporation at $40^{\circ} \mathrm{C}$. After centrifugation (3000 rpm, 5min), the organic phase and transferred. The extract was concentrated under a gentle stream of nitrogen and the final extract volume was $1.0 \mathrm{~mL}$. After filtration through $0.22-\mu \mathrm{m}$ filter units (hydrophobic), the treated sediment extracts were determinated for PCP using HPLC.

The dried samples of root tissue, shoot tissue collected in every month were separately combined at the end of experiment to determin the PCP concentrations in the plant tissue. PCP was extracted from each plant part $(5 \mathrm{~g})$ by ultrasonic extraction for $30 \mathrm{~min}$ with $30 \mathrm{~mL}$ of $\mathrm{n}$-hexane / dichloromethane $(1: 1, \mathrm{v}: \mathrm{v})$ and the same extraction was performed triple. The combined extract was deeply filtrated by glass microfiber filters (GF/C, whatman) and concentrated to about $3 \mathrm{~mL}$ and treated with $3 \mathrm{~mL}$ of concentrated $\mathrm{H}_{2} \mathrm{SO}_{4}$. All the concentrated extracts were cleaned and fractionated on a $1 \mathrm{~cm}$ i.d. silica/ anhydrous sodium sulfate alumina column packed, from the bottom to top, with silica gel $(15 \mathrm{~cm})$, anhydrous sodium sulfate $(15 \mathrm{~cm})$. The mixture was eluted with $90 \mathrm{ml}$ of $\mathrm{n}$-hexane: dichloromethane $(1: 1, \mathrm{v}: \mathrm{v})$. The extract was concentrated and solvent-exchanged to methanol under a gentle stream of nitrogen and the final extract volume of macrophyte was $1.0 \mathrm{~mL}$. After filtration through $0.22-\mu \mathrm{m}$ filter units (hydrophobic), the treated plant extracts were determinated for PCP using HPLC.

PCP analysis.Quantitative analysis of PCP was performed by an HPLC (Waters Alliance e2695-2489,USA) equipped with UV spectrophotometric detector. A C18 column $(4.6 \mathrm{~mm} \times 150$ mm I.D.; 5- $\mu \mathrm{m}$ particle size) from Waters was used. The Chromatographic condition for PCP determination was: the flow rate was $1.0 \mathrm{~mL} / \mathrm{min}$ and the mobile phase was water : methanol (20:80), The detection wavelength was $305 \mathrm{~nm}$, and the column temperature was $35^{\circ} \mathrm{C}$.

\section{Results and Discussions}

Removal Rates of PCP. After 120 days, approximately 33\% of PCP was disappeared in the control sediment, whereas seven species of aquatic macrophytes significantly facilitated removal rates $(60 \%-98 \%)$ of PCP in the treatment sediments(Fig.1, $p<0.01)$. Among all , Canna indica L., Acorus calamus L. and Iris tectorum Maxim. exhibited the fastest PCP Removalremoval rates, which attained 98\%, 92\% and 88\% of PCP removal in sediments, respectively. Thus, Those three species of aquatic macrophytes can be used as efficient alternative plants for remediation of PCP contaminated sediment, especially for Canna indica $L$. . 


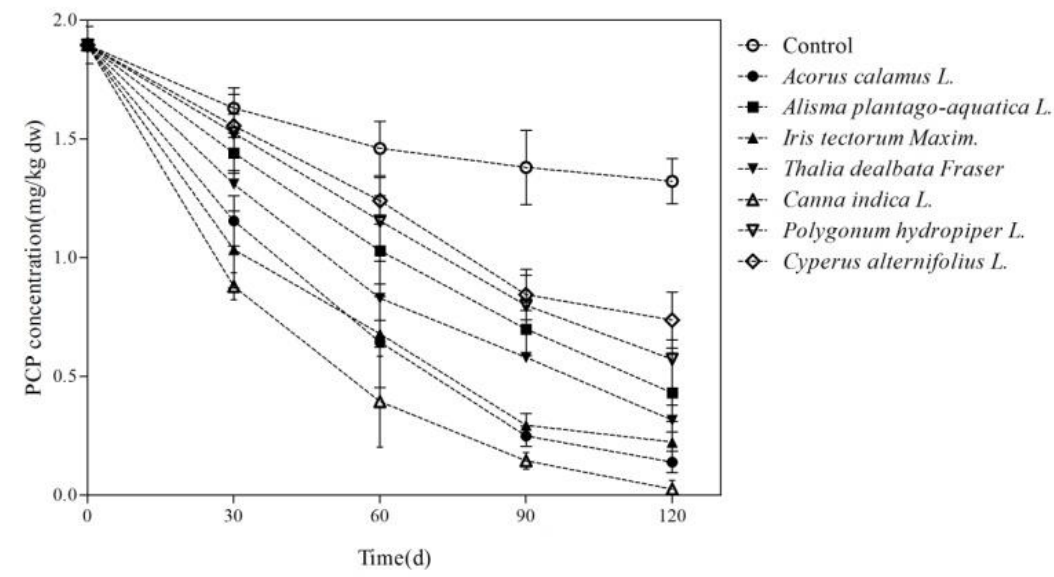

Fig.1 Changes of PCP concentrations in the control sediment and treatment sediment.

PCP Accumulation by Macrophytes.The contribution of plant uptake and accumulation to the removalremoval of organic pollutants was negligible contrary to the heavy metal remediated by plants[7-8]. In the phytoremediation process, PCP accumulation in seven aquatic macrophyte samples was further determined after 120 days and was shown in Figure 2. PCP was detected only in root tissues (approximately 100-500 $\mu \mathrm{g} / \mathrm{kg} \mathrm{dw}$ ) and no PCP was detected in all shoot tissues for seven species of aquatic macrophytes, which indicated that PCP was hard to translocated up to the shoot tissue, which was accordant with the previous research[9]. Previous research demonstrated that organics that is most likely to be taken up by plants are moderately hydrophobic compounds with Log Kow ranging from 0.5 to 3[9]. Since the Log Kow of PCP was 5.01, which might made it difficult to transport from root tissue to upper part tissue[5].

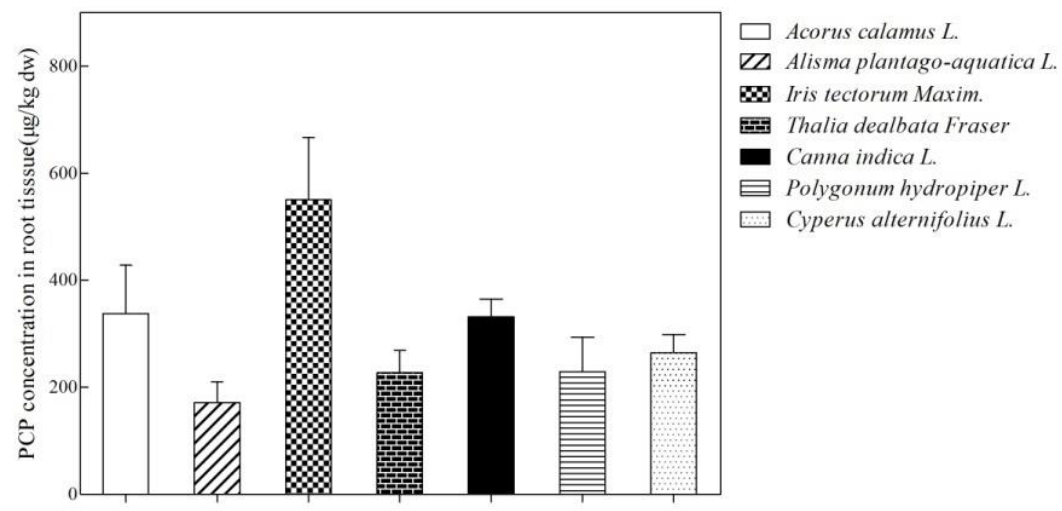

Fig.2 PCP concentrations detected in the root tissue of seven species of aquatic macrophytes.

Analysis of PCP Removal Pathways. Removal of PCP in the control sediment can be ascribed mainly to photolysis, microbial degradation and other abiotic losses. After 120 days, $33.2 \%$ of PCP was removed from the control sediment, control of light-deprived accounted for $28.75 \%$ of PCP removal, this means photolysis contributed to about $4.45 \%$ of the total losses. Nevertheless, the removal of PCP in the control of microbe-inhibited was only $8.68 \%$. That is PCP losses by photolysis and abotic losses was $4.23 \%$. Thus, The above results indicated that indigenous microbial was predominant factor (74\%) that contribute to PCP loss in the sediment control, and losses by photolysis (14\%) and abotic losses $(12 \%)$ were a miner possible pathway of PCP removal.

Removal of PCP in treatment sediment can include above contributors and plant uptake(Fig.3). PCP removal by abiotic losses in treatment sediments was approximately equal to those in corresponding control sediments as found by others [10]. 98\% of PCP was dissipated after planting. PCP accumulation by Canna indica L. contributed to approximately $0.7 \%$ of PCP removal base on the biomass of roots(approximately $0.41 \mathrm{~kg}, \mathrm{dw}$ ). Microbial degradation was calculated as: removal $\operatorname{rate}(\%)=\mathrm{TL}(\%)-\mathrm{GC}(\%)-\mathrm{PU}(\%)$, where $\mathrm{TL}$ is total loss in treatment sediment; $\mathrm{CG}$ was the contributors(photolysis+abotic losses) in control sediment; PU was the contribution by plant uptake. Obviously, approximately $90.4 \%$ of PCP was dissipated by macrophyte-promoted microbial 
degradation. Those results further conforming that microbial metabolism and biostimulation of microbial communities by planting are the main mechanism for the removal of PCP in treatment sediment.

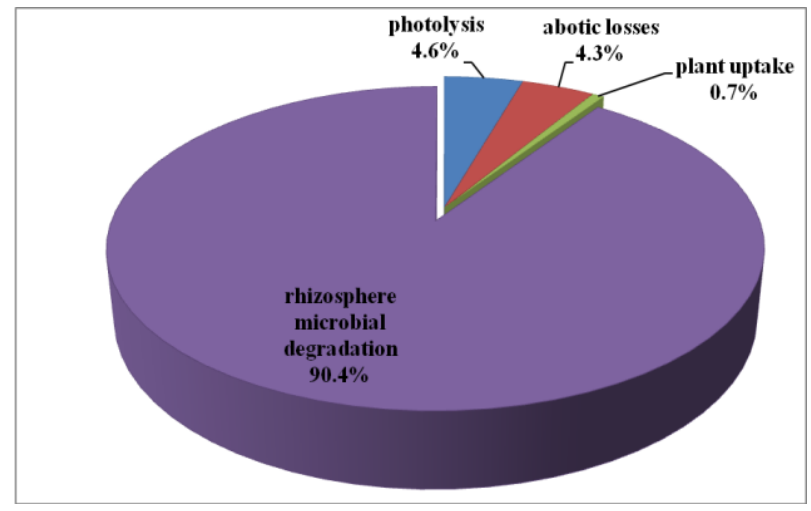

Fig.3 Contribution proportion of PCP removal pathway in treatment sediment.

\section{Summary}

The present study demonstrated that the microbial metabolism by planting with aquatic macrophytes was the main mechanism for the phytoremediation of PCP contaminated sediment. The presence of seven common species of aquatic macrophytes significantly increased the PCP removal, especially for Canna indica L., which attained $98 \%$ of PCP removal. PCP was detected only in root tissues and the accumulation of PCP in plant biomass only made a small contribution to the total removal of PCP, and approximately $90.4 \%$ of PCP was dissipated by macrophyte-promoted microbial degradation.

\section{Acknowledgments}

The research was financially supported by National Natural Science Foundation of China (Grant No.51309020) and Non-profit Industry Financial Program of MWR (Grant No.201501042, 201501019, 201401020) and Special fund for basic scientific research business of central public research institutes(Grant No. CKSF2015016).

\section{References}

[1] Zheng, W., H. Yu, W. Xia, and W. Qu. Environ. Int Vol. 42(2012), p.105-16.

[2] Yi, C., S. Yu, T. Song, Y. Li, H. Liu, X. Zhang, G. Su, L. Bing, H. Yu, and J.P. Giesy. Sci. Total. Environ Vol. 541(2016), p.65-73.

[3] Tang, Z.W., Z.F. Yang, Z.Y. Shen, and J.F. Niu.Bull. Environ. Contam. Toxicol Vol. 78(2007), p.158-62.

[4] Zheng, W., X. Wang, H. Yu, X. Tao, Y. Zhou, and W. Qu. Environ. Sci. Technol Vol. 45(2011), p. $4668-4675$.

[5] Zhao, L., C. Zhu, C. Gao, J. Jiang, J. Yang, and S. Yang. Environ. Earth Sci Vol. 64(2011), p.581-588.

[6] Hechmi N, Aissa N B, Abdenaceur H and Jedidi N. Int. J. Phytorem Vol. 16(2014), p.1241-1256.

[7] Pilon-Smits, E., Phytoremediation. Annu. Rev. Plant Biol Vol. 56(2005),p. 15-39.

[8] Burken, J.G. and J.L. Schnoor. Environ. Sci. Technol Vol.32(1998),p. 3379-3385.

[9] Alkorta, I. and C. Garbisu. Bioresour. Technol Vol. 79(2001), p. 273-276.

[10] Reilley, K.A., M.K. Banks, and A.P. Schwab. J. Environ. QualVol. 25(1996): p. 212-219. 